\title{
Determination of Fractional Chromatic Numbers in the Operation of Adding Two Different Graphs
}

\section{Penentuan Bilangan Kromatik Fraksional pada Operasi Penjumlahan Dua Graf berbeda}

\author{
Junianto Sesa ${ }^{1 *}$, Siswanto $^{2 *}$
}

\begin{abstract}
The development of graph theory has given an enormous contribution to mathematics. One of which is graph coloring and its relevance spreads in various fields, namely index coding index theory used in computing. Fractional coloring presents a binary pigment at a vertex with a different color adjoining the other distinctive colors. In operating a graph, the process is done by summation. Vertex coloring can be applied to a graph that resulted from a certain chart. In this case, the graph summation outcome of the path graph and graph cycle will emerge into an identical chromatic fraction number as the sum of the fractional chromatic numbers on each graph before it is operated, $\chi_{f}(G)=\chi_{f}\left(P_{n}\right)+\chi_{f}\left(C_{m}\right)$.
\end{abstract}

Keywords: Graph, Fractional, Chromatic

\begin{abstract}
Abstrak
Perkembangan teori graf telah banyak memberikan kontribusi kepada ilmu matematika, salah satunya adalah pewarnaan graf, dan aplikasinya yang tersebar dalam berbagai bidang salah satunya pada teori indeks koding yang digunakan pada komputasi. Pewarnaan fraksional adalah pemberian warna ganda pada titik dengan warna yang berbeda dengan titik yang bertetangga memiliki warna yang berbeda. Dalam operasi-operasi pada graf dikenal adalah operasi penjumlahan. Pewarnaan titik dapat diterapkan pada graf yang merupakan hasil operasi dari beberapa graf khusus. Dalam hal ini graf hasil penjumlahan graf lintasan dan graf siklus akan menghasilkan bilangan kromatik fraksional yang sama dengan penjumlahan bilangan kromatik fraksional masing-masing graf sebelum dioperasikan, $\chi_{f}(G)=\chi_{f}\left(P_{n}\right)+$ $\chi_{f}\left(C_{m}\right)$.
\end{abstract}

Kata kunci: Graf, Fraksional, Kromatik

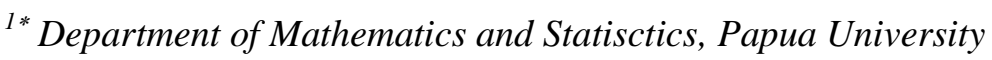

Email address: j.sesa@unipa.ac.id

${ }^{2 *}$ Departement of Statistics, Hasanuddin University

Email address: siswanto@unhas.ac.id
}

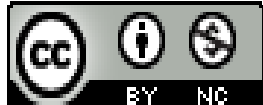

This work is licensed under a Creative Commons Attribution-NonCommercial 4.0 International License 


\section{Jurnal Matematika, Statistika \& Komputasi Junianto Sesa, Siswanto}

\section{PENDAhUluAN}

Teori graf merupakan salah satu bagian dari ilmu matematika dan dapat digunakan untuk menyelesaikan permasalahan diskrit. Keunikan teori graf adalah kesederhanaan pokok bahasan yang dipelajarinya, karena dapat disajikan dalam bentuk pasangan himpunan benda-benda yang disebut titik dan yang menghubungkan titik yaitu garis-garis yang biasa disebut sisi. Titik menggambarkan objek-objek tertentu dan sisi menggambarkan hubungan antara objek-objek tersebut [6].

Seiring dengan kemajuan ilmu pengetahuan dan teknologi akhir-akhir ini, banyak sekali penelitian terbaru tentang graf, mulai dari jenis-jenis graf, pewarnaan graf, bilangan ramsey, differensial graf, dan lain-lain. Aplikasinya yang tersebar dalam berbagai bidang seperti pada jaringan media sosial, dan kampanye politik. Bilangan kromatik fraksional diperoleh setelah memberi warna ganda pada setiap titik di graf sedemikian sehingga setiap titik yang diberi warna ganda berbeda jika titik tersebut bertetangga dan banyaknya warna minimum yang digunakan disebut bilangan kromatik fraksional [10].

Graf cocktail party merupakan graf pertama yang ditemukan bilangan kromatik fraksionalnya oleh Roberts [17], namun kekurangannya adalah tidak menjelaskan secara mendalam mengenai batasan dalam mewarnai. Pada 1979 Bollobás dkk [20], juga menemukan bilangan kromatik fraksional graf web, helm, bipartit, dan tripartit dengan menjelaskan lebih rinci bahwa bilangan kromatik fraksional tidak hanya bilangan bulat tetapi ada juga dalam pecahan. Setelah itu, Saaty dkk [13] menentukan bilangan kromatik graf Pan dengan menerapkan empat warna dalam satu titik.

Pada tahun 1990 Skiena [15] menemukan bilangan kromatik fraksional pada graf siklus, bintang dan roda sekaligus menjelaskan perbandingan antara bilangan kromatik dan bilangan kromatik fraksional, Selanjutnya, Larsen dan Ullman [14] mengembangkan kontruksi graf Mycielski dan mencari bilangan kromatik fraksionalnya, hingga sekarang Ullman masih menggeluti bidang ini dimana sekarang beliau sedang menyusun buku dengan judul "Fractional Graph Theory" yang berisi seluruh pembahasan pewarnaan fraksional.

Godsil dan Royle [10] juga meneliti bilangan kromatik fraksional dari graf lintasan dengan mengambil dasar dari beberapa peneliti sebelumnya. Dengan berjalannya waktu Pirnazar dan Ullman [16] kembali menemukan bilangan kromatik fraksional pada graf planar dengan mengkontruksi beberapa graf diantaranya adalah graf bintang dan graf lengkap. Golin [11] juga pada tahun 2004 mengembangkan pewarnaan fraksional dengan menerapkannya pada graf antiprisma dan graf pohon kemudian membandingkan hasilnya.

Dengan berkembangnya banyak kontruksi graf baru maka peneliti dibidang pewarnaan graf juga semakin giat dalam mencari bilangan kromatik fraksional dari graf-graf tersebut. Ghost dkk [9] pada tahun 2006 meneliti bilangan kromatik dari graf barbel. Kemudian disusul oleh Bryant [5] Bilangan kromatik fraksional graf lengkap dengan menerapkan unsur ketetanggaan. Pada tahun 2008 Anitha [1] diperoleh lagi bilangan kromatik fraksional graf matahari dan graf sunlet, diikuti pada tahun 2011 Ullman dkk [18] kembali meneliti bilangan kromatik fraksional graf kneser, kosong, dan prisma.

Dengan berkembangnya dunia teknologi maka banyak peneliti mulai melirik beberapa bentuk graf yang bisa diaplikasikan kedalam perangkat-perangkat modern. salah satunya adalah bilangan kromatik fraksional, dimana beberapa peneliti sudah tidak mengkontruksi graf baru tetapi mencari dimana dapat diaplikasikan hasil penelitian mengenai pewarnaan graf. Pada tahun 2013 Graf $K_{\Delta}$-free [8] yang merupakan kontruksi dari graf kneser dipakai dalam indeks pengkodean dimana yang ditinjau adalah bilangan kromatik fraksionalnya, dijelaskan bahwa dalam membuat indeks pengkodean yang paling optimal yaitu dengan menggunakan pewarnaan fraksional. Kemudian Zdenek Dvorak dkk [7] juga menemukan bilangan kromatik fraksional pada Graf Subcubic triangle-free dimana diaplikasikan pada pemrograman komputasi. Tahun 2014 banyak 


\section{Jurnal Matematika, Statistika \& Komputasi}

\section{Junianto Sesa, Siswanto}

peneliti mulai tertarik mengkontruksi beberapa graf menjadi satu graf baru sesuai dengan bentuk yang diinginkan agar dalam diaplikasikan dalam indeks kode, salah satunya adalah Kneser Hyper Graf [2] yang juga merupakan kontruksi dari graf kneser.

Hingga saat ini banyak peneliti telah mengeluarkan jurnal yang berkaitan dengan pewarnaan fraksional yang diaplikasikan dalam bidang komputer, salah satunya oleh Fatemeh Arbabjolfaei dan Young-Han Kim [3] pada tahun 2015, menjelaskan bahwa masalah indeks kode khusus kapasitas region dari masalah yang terkecil pada saat terjadi interaksi yang tidak ada, satu jalur ataupun yang kompleks dapat diselesaikan menggunakan pewarnaan fraksional dimana bilangan kromatik fraksional yang kecil sangat membantu dalam pembuatan indeks kode.

Pada tahun 2018 Junianto dkk [12] juga melakukan penelitian untuk menentukan bilangan kromatik fraksional dari operasi amalgamasi graf lintasan dan graf siklus, penelitian tersebut terbagi atas dua yaitu, amalgamasi sisi dan amalgamasi titik.

Berdasarkan uraian diatas penulis tertarik untuk melihat bilangan kromatik fraksional graf hasil dari operasi penjumlahan dua graf berbeda, yang akan menghasilkan satu graf baru sehingga bilangan kromatik dari graf tersebut akan dipengaruhi oleh salah satu bilangan kromatik fraksional dari salah satu graf sebelum dioperasikan.

Agar dapat memahami mengenai pewarnaan pada graf serta operasi penjumlahan, maka diberikan beberapa definisi dan teorema berkaitan dengan pembahasan tersebut.

Definisi 1.1. Graf $G$ adalah pasangan $(V(G), E(G))$, dimana $V(G)$ adalah himpunan berhingga tidak kosong, yang elemen-elemennya disebut titik, dan $E(G)$ adalah himpunan pasanganpasangan tak berurut dari elemen-elemen $V(G)$ yang berbeda disebut sisi [6].

Definisi 1.2. Pewarnaan titik adalah memberikan warna pada titik-titik pada graf sedemikian sehingga setiap dua titik yang bertetangga mempunyai warna yang berbeda.

Definisi 1.3. diberikan graf tak berarah $G=(V, E)$, himpunan bebas adalah himpunan bagian dari titik $U \subseteq V$, sedemikian sehingga tidak ada dua titik di $U$ yang bertetangga [4].

Definisi 1.4. Bilangan kromatik fraksional pada graf sederhana $G(V, E)$ didefinisikan dengan $\chi_{f}(G)$ diberikan oleh $\min \sum_{I \in J} x_{I}$

$$
\begin{gathered}
\sum_{I: v \in I} x_{I} \geq 1, v \in V, x:[N]^{k} \rightarrow \mathbb{R}^{+} \\
\quad x_{I} \in \mathbb{R}^{+}, \forall I \in \mathcal{J} \\
x\left(u_{i}\right)=\left|\frac{A_{i}}{\bigcup_{j=1}^{i-1} A_{j}}\right|, \forall i, j \in \mathbb{N}
\end{gathered}
$$

Dengan I himpunan dari semua himpunan bebas di $G, \mathbb{R}^{+}$bilangan riil positif [20].

Definisi 1.5. Graf jumlah $G+H$ adalah graf baru dengan himpunan titik $V(G+H)=V(G) \cup$ $V(H)$ dan himpunan sisi $E(G+H)=E(G) \cup E(H) \cup\{u v: u \in V(G), v \in V(H)\}[6]$.

\section{Contoh 1.1.}
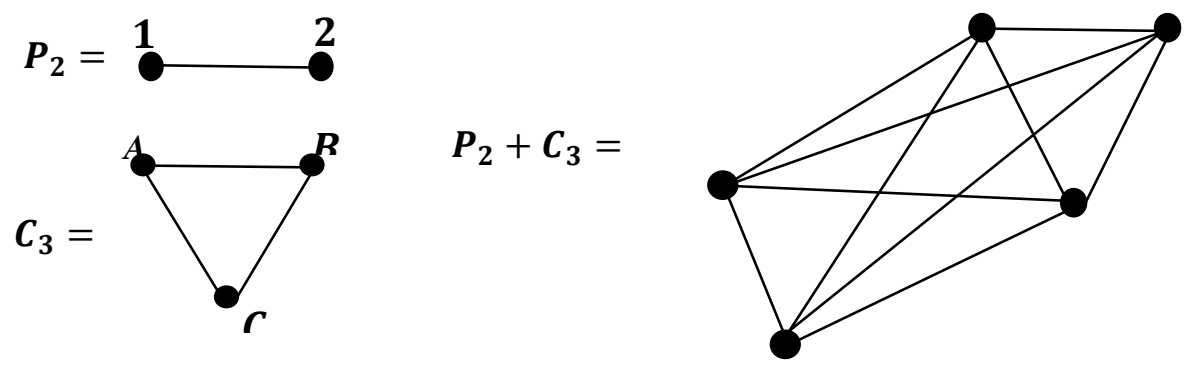

Gambar 1.1. Contoh operasi Penjumlahan graf 


\section{Jurnal Matematika, Statistika \& Komputasi}

\section{Junianto Sesa, Siswanto}

\section{DISKUSI}

Dalam mencari bilangan kromatik fraksional graf dengan menggunakan metode kajian pustaka, langkah - langkah yang digunakan dalam penelitian ini adalah :

1. Mengumpulkan bahan literatur serta studi kepustakaan yang berhubungan dengan graf.

2. Menggambar graf tak terhubung tanpa loop untuk dan dengan $n$ adalah titik dan $m$ adalah garis.

3. Mengelompokkan graf tak terhubung untuk garis maksimal yang sama.

4. Menghitung jumlah graf tak terhubung untuk setiap garis.

5. Melihat pola banyaknya graf yang terbentuk.

6. Memberi warna pada titik graf (dalam 1 titik lebih dari satu warna)

7. Menarik kesimpulan.

Seperti diketahui bahwa bilangan kromatik fraksional pada setiap graf ada yang bernilai bilangan bulat tetapi ada juga yang merupakan pecahan. Pewarnaan Fraksional merupakan topik baru dari generalisasi pewarnaan graf biasa di teori graph yang dikenal sebagai teori graf fraksional. Dalam pewarnaan graf fraksional, setiap titik dalam graf diberi beberapa warna, dan titik yang bertetanga atau terhubung oleh sisi harus diberi warna yang berbeda. Namun dalam pewarnaan fraksional, satu himpunan diberi warna yang sama pada setiap titik dari graf. Pewarnaan fraksional graf dapat dilihat sebagai relaksasi pemrograman linear dari pewarnaan graf. Masalah pewarnaan fraksional jauh lebih baik digunakan untuk pendekatan pemrograman linear dari masalah pewarnaan biasa.

Graf seringkali dikontruksi sesuai dengan kebutuhan sedemikian sehingga membentuk suatu graf yang dapat diaplikasikan dalam dunia teknologi, maka sering di gunakan operasi graf dalam mengkontruksi.

Bilangan kromatik fraksional pada operasi penjumlahan graf lintasan dan graf siklus yang sebagai berikut,

a) Misal diberikan graf lintasan $\mathrm{P}_{2}$ dengan $V\left(\mathrm{P}_{2}\right)=\left\{\mathrm{u}_{1}, \mathrm{u}_{2}\right\}$ dan $E\left(\mathrm{C}_{3}\right)=\left\{\mathrm{u}_{1} \mathrm{u}_{2}, \mathrm{u}_{2} \mathrm{u}_{3}\right\}$ dan graf siklus $\mathrm{C}_{3}$ dengan $V\left(\mathrm{C}_{3}\right)=\left\{\mathrm{v}_{1}, \mathrm{v}_{2}, \mathrm{v}_{3}\right\}$ dan $E\left(\mathrm{C}_{3}\right)=\left\{\mathrm{v}_{1} \mathrm{v}_{2}, \mathrm{v}_{2} \mathrm{v}_{3}, \mathrm{v}_{3} \mathrm{v}_{1}\right\}$, maka himpunan bebas minimum dari $\mathrm{P}_{2}+\mathrm{C}_{3}$ adalah

$$
\begin{aligned}
& I_{1}=\left\{\mathrm{v}_{1}\right\} \\
& I_{2}=\left\{\mathrm{v}_{2}\right\} \\
& I_{3}=\left\{\mathrm{u}_{1}\right\} \\
& I_{4}=\left\{\mathrm{u}_{2}\right\} \\
& I_{5}=\left\{\mathrm{u}_{3}\right\}
\end{aligned}
$$

maka himpunan dari semua himpunan bebas $\mathcal{J}=\left\{I_{1}, I_{2}, I_{3}, I_{4}, I_{5}\right\}$.

diberikan $I: V\left(P_{2}\right) \rightarrow[N]^{2}$

dan $I: V\left(C_{3}\right) \rightarrow[N]^{2}$

$$
\mathrm{u}_{1} \rightarrow\{1,2\}=A_{1}, \quad \mathrm{u}_{2} \rightarrow\{3,4\}=A_{2}
$$

$x:[N]^{2} \rightarrow \mathbb{R}^{+}$

$$
\mathrm{v}_{1} \rightarrow\{5,6\}=A_{3}, \quad \mathrm{v}_{2} \rightarrow\{7,8\}=A_{4}, \quad \mathrm{v}_{3} \rightarrow\{9,10\}=A_{5}
$$

$$
\begin{gathered}
x\left(\mathrm{u}_{1}\right)=\frac{\left|A_{1}\right|}{2}=\frac{2}{2} \\
x\left(\mathrm{u}_{2}\right)=\frac{\left|A_{2} / A_{1}\right|}{2}=\frac{2}{2} \\
x\left(\mathrm{v}_{1}\right)=\frac{\left|A_{3} /\left(A_{1} \cup A_{2}\right)\right|}{2}=\frac{2}{2} \\
x\left(\mathrm{v}_{2}\right)=\frac{\left|A_{4} /\left(A_{1} \cup A_{2} \cup A_{3}\right)\right|}{2}=\frac{2}{2}
\end{gathered}
$$




\section{Jurnal Matematika, Statistika \& Komputasi}

\section{Junianto Sesa, Siswanto}

maka bilangan fraksional adalah

$$
x\left(\mathrm{v}_{3}\right)=\frac{\left|A_{5} /\left(A_{1} \cup A_{2} \cup A_{3} \cup A_{4}\right)\right|}{2}=\frac{2}{2}
$$

$$
\sum_{I: u_{i} \in I, \forall I \in J_{2}} x_{I}=\frac{2}{2}+\frac{2}{2}+\frac{2}{2}+\frac{2}{2}+\frac{2}{2}=\frac{10}{2}=5
$$

Diberikan $I: V\left(P_{2}\right) \rightarrow[N]^{3}$

dan $I: V\left(C_{3}\right) \rightarrow[N]^{3}$

$$
\mathrm{u}_{1} \rightarrow\{1,2,3\}=A_{1}, \quad \mathrm{u}_{2} \rightarrow\{4,5,6\}=A_{2}
$$

$$
\begin{aligned}
& \mathrm{v}_{1} \rightarrow\{7,8,9\}=A_{3}, \quad \mathrm{v}_{2} \rightarrow\{10,11,12\}=A_{4}, \quad \mathrm{v}_{3} \rightarrow\{13,14,15\}=A_{5} \\
& x:[N]^{3} \rightarrow \mathbb{R}^{+} \\
& x\left(\mathrm{u}_{1}\right)=\frac{\left|A_{1}\right|}{3}=\frac{3}{3} \\
& x\left(\mathrm{u}_{2}\right)=\frac{\left|A_{2} / A_{1}\right|}{3}=\frac{3}{3} \\
& x\left(\mathrm{v}_{1}\right)=\frac{\left|A_{3} /\left(A_{1} \cup A_{2}\right)\right|}{3}=\frac{3}{3} \\
& x\left(\mathrm{v}_{2}\right)=\frac{\left|A_{4} /\left(A_{1} \cup A_{2} \cup A_{3}\right)\right|}{3}=\frac{3}{3} \\
& x\left(\mathrm{v}_{3}\right)=\frac{\left|A_{5} /\left(A_{1} \cup A_{2} \cup A_{3} \cup A_{4}\right)\right|}{3}=\frac{3}{3}
\end{aligned}
$$

maka bilangan fraksional adalah

diberikan $I: V\left(P_{2}\right) \rightarrow[N]^{4}$

$$
\sum_{I: u_{i} \in I, \forall I \in \mathcal{J}_{3}} x_{I}=\frac{3}{3}+\frac{3}{3}+\frac{3}{3}+\frac{3}{3}+\frac{3}{3}=\frac{15}{3}=5
$$

dan $I: V\left(C_{3}\right) \rightarrow[N]^{4}$

$$
\mathrm{u}_{1} \rightarrow\{1,2,3,4\}=A_{1}, \quad \mathrm{u}_{2} \rightarrow\{5,6,7,8\}=A_{2}
$$

$\mathrm{v}_{1} \rightarrow\{9,10,11,12\}=A_{3}, \quad \mathrm{v}_{2} \rightarrow\{13,14,15,16\}=A_{4}, \quad \mathrm{v}_{3} \rightarrow\{17,18,19,20\}=A_{5}$ $x:[N]^{4} \rightarrow \mathbb{R}^{+}$

$$
\begin{gathered}
x\left(\mathrm{u}_{1}\right)=\frac{\left|A_{1}\right|}{4}=\frac{4}{4} \\
x\left(\mathrm{u}_{2}\right)=\frac{\left|A_{2} / A_{1}\right|}{4}=\frac{4}{4} \\
x\left(\mathrm{v}_{1}\right)=\frac{\left|A_{3} /\left(A_{1} \cup A_{2}\right)\right|}{4}=\frac{4}{4} \\
x\left(\mathrm{v}_{2}\right)=\frac{\left|A_{4} /\left(A_{1} \cup A_{2} \cup A_{3}\right)\right|}{4}=\frac{4}{4} \\
x\left(\mathrm{v}_{3}\right)=\frac{\left|A_{5} /\left(A_{1} \cup A_{2} \cup A_{3} \cup A_{4}\right)\right|}{4}=\frac{4}{4}
\end{gathered}
$$

maka bilangan fraksional adalah

$$
\sum_{I: u_{i} \in I, \forall I \in J_{4}} x_{I}=\frac{4}{4}+\frac{4}{4}+\frac{4}{4}+\frac{4}{4}+\frac{4}{4}=\frac{20}{4}=5
$$

diberikan $I: V\left(P_{2}\right) \rightarrow[N]^{5}$

dan $I: V\left(C_{3}\right) \rightarrow[N]^{5}$

$$
\mathrm{u}_{1} \rightarrow\{1,2,3,4,5\}=A_{1}, \quad \mathrm{u}_{2} \rightarrow\{6,7,8,9,10\}=A_{2}
$$

$$
\begin{gathered}
\mathrm{v}_{1} \rightarrow\{11,12,13,14,15\}=A_{3}, \quad \mathrm{v}_{2} \rightarrow\{16,17,18,19,20\}=A_{4}, \\
\mathrm{v}_{3} \rightarrow\{21,22,23,24,25\}=A_{5}
\end{gathered}
$$

$x:[N]^{5} \rightarrow \mathbb{R}^{+}$ 


\section{Jurnal Matematika, Statistika \& Komputasi}

$$
\begin{gathered}
\text { Junianto Sesa, Siswanto } \\
x\left(\mathrm{u}_{1}\right)=\frac{\left|A_{1}\right|}{5}=\frac{5}{5} \\
x\left(\mathrm{u}_{2}\right)=\frac{\left|A_{2} / A_{1}\right|}{5}=\frac{5}{5} \\
x\left(\mathrm{v}_{1}\right)=\frac{\left|A_{3} /\left(A_{1} \cup A_{2}\right)\right|}{5}=\frac{5}{5} \\
x\left(\mathrm{v}_{2}\right)=\frac{\left|A_{4} /\left(A_{1} \cup A_{2} \cup A_{3}\right)\right|}{5}=\frac{5}{5} \\
x\left(\mathrm{v}_{3}\right)=\frac{\left|A_{5} /\left(A_{1} \cup A_{2} \cup A_{3} \cup A_{4}\right)\right|}{5}=\frac{5}{5}
\end{gathered}
$$

maka bilangan fraksional adalah

dst.

$$
\sum_{I: u_{i} \in I, \forall I \in \mathcal{J}_{3}} x_{I}=\frac{5}{5}+\frac{5}{5}+\frac{5}{5}+\frac{5}{5}+\frac{5}{5}=\frac{25}{5}=5
$$

Sehingga bilangan fraksionalnya $\{5,5,5,5,5, \ldots\}$, dan bilangan kromatik fraksionalnya

$$
\min \sum_{I: u_{i} \in I, \forall I \in J_{k}} x_{I}=\min \{5,5,5,5,5, \ldots\}=5
$$

untuk lebih jelas perhatikan gambar berikut ini

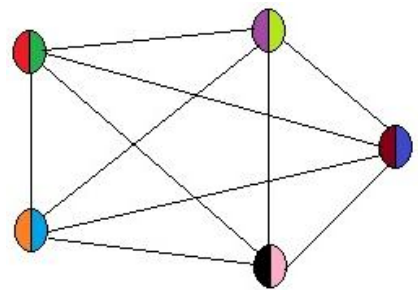

Gambar 2.1. Bilangan Kromatik Fraksional Graf $\mathrm{P}_{2}+\mathrm{C}_{3}$

Berdasarkan hasil diatas maka diperoleh teorema sebagai berikut

\section{Teorema 2.1}

Jika $G$ graf hasil operasi penjumlahan graf lintasan dan graf siklus maka bilangan kromatik fraksionalnya adalah $\chi_{f}(G)=\chi_{f}\left(P_{n}\right)+\chi_{f}\left(C_{m}\right)$.

Bukti:

Misal diberikan graf lintasan $P_{n}$ dan graf siklus $C_{m}$, jika $G$ merupakan graf hasil operasi penjumlahan graf siklus dan graf lintasan maka setiap titik pada graf $P_{n}$ bertetangga pada setiap titik pada graf $C_{m}$, sehingga titik graf $P_{n}$ diberi warna berbeda dengan graf $C_{m}$. Selanjutnya untuk menentukan bilangan kromatik fraksional penjumlahan graf $P_{n}$ dan $C_{m}$ adalah dengan menetukan bilangan kromatik fraksional masing-masing graf sebelum dijumlahkan, diperoleh $\chi_{f}\left(P_{n}\right)$ dan $\chi_{f}\left(C_{m}\right)$. Karena setiap titik $P_{n}$ bertetangga dengan titik $C_{m}$ maka bilangan kromatik fraksional $\chi_{f}\left(P_{n}, V+C_{m}, V\right)=\chi_{f}\left(P_{n}\right)+\chi_{f}\left(C_{m}\right)$.

\section{KESIMPULAN}

Bilangan kromatik fraksional sangat berguna dalam dunia teknologi terutama dibidang indeks kode. Bilangan kromatik fraksional dari beberapa graf jika digabung menggunakan operasi penjumlahan maka hasilnya adalah jumlah bilangan kromatik fraksional setiap graf sebelum dilakukan operasi. 


\section{Jurnal Matematika, Statistika \& Komputasi}

\section{REFERENCES}

\section{Junianto Sesa, Siswanto}

[1] Anitha R., \& Lekshmi R S., 2008. N-Sun Decomposition of Complete, Complete Bipartite and Some Harary Graphs. International Journal of Computational and Mathematical Sciences, Vol. 2, No. 1, 33-38.

[2] Araujo-Pardo G., Diaz P J C., \& Oliveros D., 2016. The (p, q)-extremal Problem and the Fractional Chromatic Number of Kneser Hypergraphs. Discrete Mathematics, Vol. 339, No. $11,2819-2825$.

[3] Arbabjolfaei F., \& Kim Y H., 2015. Structural Properties of Index Coding Capacity Using Fractional Graph Theory. IEEE International Symposium on Information Theory (ISIT), thn 2015, 1034-1038. University of California, San Diego.

[4] Bondy J A., 1978. A remark on two sufficient conditions for Hamilton cycles. Discrete Mathematics, Vol. 22, No. 2, 191-193.

[5] Bryant D., Cycle Decompositions of Complete Graphs. London Mathematical Society Lecture Note, 346, 67. Cambridge, England.

[6] Chartrand G., 1985. Introductory Graph Theory. Dover, New York.

[7] Dvorak Z., Sereni J S., \& Volec J., 2014. Subcubic Triangle-free Graphs have Fractional Chromatic Number at Most 14/5. Journal of the London Mathematical Society, Vol. 89, No. 3, 641-662.

[8] Edwards K., \& King A D., 2013. Bounding the Fractional Chromatic Number of $K_{\Delta}$ Free Graphs. Siam Journal on Discrete Mathematics, Vol. 27, No. 2, 1184-1208.

[9] Ghosh A., Boyd S., \& Saberi A., 2008. Minimizing Effective Resistance of a Graph. Proceeding 17th International Symposium Mathematics the Network and Systems, thn 2008, 37-66. Kyoto, Japan.

[10] Godsil C., \& Royle G., 2001. Fractional Chromatic Number. Springer Verlag, New York.

[11] Golin M J., \& Leung Y C., 2004. Unhooking Circulant Graphs: A Combinatorial Method for Counting Spanning Trees and Other Parameters. International Workshop on GraphTheoretic Concepts in Computer Science, thn 2004, 296-307. Springer, Heidelberg, Berlin.

[12] Junianto S., Armin L., Hasmawati \& Siswanto., 2018. Determination of Fractional Chromatic Number on Two Different Graphs of Amalgamation Operation. International Journal of Computer Science and Network. Vol. 7, No.3, 158-165.

[13] Kainen P C., \& Saaty T L., 1977. The Four-Color Problem: Assaults and Conquest. McGraw Hill, New York.

[14] Larsen M., Propp J., \& Ullman D., 1995. The Fractional Chromatic Number of Mycielski's Graphs. Journal of Graph Theory, Vol. 19, No. 3, 411-416.

[15] Pemmaraju S., \& Skiena S., 2003. Cycles, Stars, and Wheels. Computational Discrete Mathematics Combinatiorics and Graph Theory in Mathematica, 249-284.

[16] Pirnazar A., \& Ullman D H., 2002. Girth and Fractional Chromatic Number of Planar Graphs. Journal of Graph Theory, Vol. 39, No. 3, 201-217.

[17] Roberts F S., 1969. On the Boxicity and Cubicity of a Graph. Recent Progress in Combinatorics, Vol. 1, No. 1, 301-310.

[18] Scheinerman E R., \& Ullman D H., 2011. Fractional Graph Theory a Rational Approach to the Theory of Graphs. Dover, New York. 


\section{Jurnal Matematika, Statistika \& Komputasi}

\section{Junianto Sesa, Siswanto}

[19] Shanmugam K., Dimakis A G., \& Langberg M., 2013. Local Graph Coloring and Index Coding. IEEE International Symposium on Information Theory, thn 2013, 1152-1156. Department of Mathematics and Computer Science the Open University of Israel, Israel.

[20] Weisstein E W., 2011. Fractional Chromatic Number. https://mathworld. wolfram. com/. [11 Juni 2021]. 